\title{
A Phase II study of 5-fluorouracil and cisplatin systemic chemotherapy for inoperable hepatocellular carcinoma with $\alpha$ fetoprotein as a predictive and prognostic marker
}

\author{
BHUMSUK KEAM, DO-YOUN OH, SE-HOON LEE, DONG-WAN KIM, SEOCK-AH IM, \\ TAE-YOU KIM, DAE SEOG HEO and YUNG-JUE BANG \\ Department of Internal Medicine, Seoul National University Hospital, \\ Seoul National University College of Medicine, Seoul, Korea
}

Received January 2, 2008; Accepted February 27, 2008

\begin{abstract}
The objective of this study was to evaluate the efficacy and toxicity of 5-fluorouracil and cisplatin in patients with inoperable hepatocellular carcinoma (HCC), and to evaluate the utility of $\alpha$ fetoprotein (AFP) as a marker in assessing response to systemic chemotherapy. Fifty-seven inoperable HCC patients were enrolled. The administered regimen consisted of $60 \mathrm{mg} / \mathrm{m}^{2}$ cisplatin on day 1 followed by $1,200 \mathrm{mg} / \mathrm{m}^{2} 5$-fluorouracil on days $1-4$, repeated every 3 weeks. One patient achieved a complete response (1.8\%) and 7 a partial response $(12.3 \%)$, an overall response rate of $14.1 \%$ and a disease control rate of $43.9 \%$. Median time to progression (TTP) was 2.4 months, and median overall survival (OS) 9.8 months. The main grade 3 and 4 toxicities were leucopenia (10.5\%), neutropenia $(21.0 \%)$ and thrombocytopenia $(8.8 \%)$. Of the 45 patients with an initially elevated AFP level, $15(33.3 \%)$ showed a reduction of more than $50 \%$. The disease control rate was significantly higher in AFP responders (80.0 vs. $23.3 \%$ in AFP non-responders, $\mathrm{p}<0.001)$, who moreover exhibited prolonged TTP $(\mathrm{p}=0.010)$. Combination chemotherapy of 5-fluorouracil and cisplatin showed modest disease control activity and acceptable toxicity in patients with inoperable HCC. Furthermore, AFP response may be a useful surrogate marker for clinical outcome.
\end{abstract}

\section{Introduction}

Hepatocellular carcinoma (HCC) is one of the most common cancers worldwide, especially in Eastern Asia, where hepatitis $\mathrm{B}$ virus (HBV) is endemic. Moreover, despite improvements in screening methods, a significant number of patients are

Correspondence to: Dr Seock-Ah Im, Department of Internal Medicine, Seoul National University College of Medicine, 28 Yongon-Dong, Chongno-Gu, Seoul 110-744, Korea

E-mail:moisa@snu.ac.kr

Key words: hepatocellular carcinoma, $\alpha$ fetoprotein, 5-fluorouracil, cisplatin, chemotherapy diagnosed at an inoperable advanced stage. The common reasons for inoperability are the presence of advanced cirrhosis, metastatic lesions, and invasion or thrombosis of the major blood vessels. Treatment options are often limited for these patients due to hepatic dysfunction and the limited efficacy of systemic chemotherapy. The disappointing results of systemic chemotherapy are possibly due to multidrug resistance gene expression, which is commonly observed in $\operatorname{HCC}(1,2)$. Consequently, the use of chemotherapy in HCC remains characterized by uncertainty regarding patient survival $(3,4)$.

5-Fluorouracil (5-FU) is one of the chemotherapeutic agents most commonly used to treat HCC. Much interest has been shown in so-called 5-FU modulators, such as interferon and cisplatin, regarding their ability to increase the impact of 5-FU treatment (5-9). We therefore conducted a Phase II trial to evaluate the antitumor activity and toxicity of a systemic chemotherapy regimen based on 5-FU and cisplatin in patients with inoperable HCC.

Another problem associated with chemotherapy in HCC is the discrepancy between radiologic and biologic response. Leung et al (9) reported that patients with a radiologic partial response to chemotherapy achieved a pathologic complete response, meaning persistent lesions discerned by radiology may represent the complete pathologic resolution of viable tumor cells by chemotherapy. Thus, a traditional radiologic response does not always reflect the biologic response to chemotherapy in HCC. This difference in response might be overcome by combining radiography with the use of other markers that more accurately reflect tumor biology, such as serum $\alpha$-fetoprotein (AFP).

AFP is currently used in chronic liver disease screening, although its utility as a predictive or prognostic marker is controversial (10-12). The aims of the present study were to evaluate the efficacy and toxicity of a combined 5-FU/cisplatin regimen in patients with inoperable $\mathrm{HCC}$, and to determine whether AFP could serve as a predictive or prognostic marker of systemic chemotherapy.

\section{Materials and methods}

Patient population. From November 2001 to March 2005, 57 consecutive patients with inoperable HCC were enrolled in this study. Inoperability was due to metastatic lesions or portal 
vein thrombosis. Eligibility criteria included: i) pathologically confirmed HCC or an AFP level $\geq 400 \mathrm{ng} / \mathrm{ml}$ together with a hypervascular liver tumor and cirrhosis (13), ii) a bi-dimensionally measurable lesion, iii) ECOG (Eastern Cooperative Oncology Group) performance of 0-3, iv) Child-Pugh class A or B, and v) adequate bone marrow, hepatic and renal functions. Required laboratory data were as follows: absolute neutrophil count $\geq 1,500 / \mathrm{m}^{3}$, platelet count $\geq 50,000 / \mathrm{m}^{3}$, hemoglobin $\geq 10 \mathrm{~g} / \mathrm{dl}$, serum creatinine $<1.5 \mathrm{mg} / \mathrm{dl}$, total bilirubin $<3.0 \mathrm{mg} / \mathrm{dl}$ and serum transaminase $<2.5$ times the normal level. Patients with an active infection or a concurrent major systemic disease were excluded. Patients who had progressed or relapsed after local therapy, such as surgery, transarterial chemoembolization (TACE) or percutaneous ethanol injection were included. Serum AFP levels were measured in all patients prior to chemotherapy.

Tumor response criteria. Computed tomography was routinely performed for $\mathrm{HCC}$ using a conventional two-phase technique (arterial phase and portal venous phase). Objective tumor response was evaluated using World Health Organization criteria (14) as follows: complete response (CR) was defined as the complete disappearance of all assessable lesions; partial response (PR) as a $>50 \%$ reduction in the sum of the products of the longest perpendicular diameters of all the measurable lesions for a period of $\geq 4$ weeks; stable disease (SD) as a $<50 \%$ reduction or a $<25 \%$ increase in the sum of the products of the longest perpendicular diameters of all the measurable lesions for a period of $\geq 4$ weeks, and progressive disease (PD) a $>25 \%$ increase in the area(s) of the original measurable lesion or the appearance of a new lesion. Computed tomography was checked after every two cycles of chemotherapy, unless there was definite evidence of disease progression. In patients who received TACE, compact lipiodol uptake lesions were considered to be necrotic (15) and were excluded from the measurable lesions for response evaluation.

To define the AFP response, we modified the tumor marker response criteria from CA-125 for ovarian cancer (16) and from prostate-specific antigen for prostate cancer (17), and evaluated the correlation between tumor marker (AFP) response and the clinical outcome of our patients. AFP responders were defined as patients showing a decline of $>50 \%$ in one serum AFP level, confirmed by a second AFP level and lasting for more than 4 weeks. Patients with a $<50 \%$ decline or a progressive AFP elevation were considered nonresponders. Baseline AFP levels for these declines were measured within the 5 days prior to the start of chemotherapy.

Toxicities were assessed according to the National Cancer Institute Common Toxicity Criteria version 2.0. Physical examinations and clinical manifestations, such as ascites and pain, were evaluated before treatment and during each chemotherapy cycle.

Treatment schedule. The 5-FU/cisplatin chemotherapeutic regimen consisted of $60 \mathrm{mg} / \mathrm{m}^{2}$ cisplatin delivered as an intravenous infusion over $15 \mathrm{~min}$ on day 1 , followed by $1,200 \mathrm{mg} /$ $\mathrm{m}^{2} 5$-FU by continuous intravenous infusion over $10 \mathrm{~h}$ on days 1-4 repeated every 3 weeks. Treatment was discontinued for patients with progressive disease or for those who refused treatment.
Table I. Patient characteristics.

\begin{tabular}{lc}
\hline Characteristics $(\mathrm{n}=57)$ & No. of patients $(\%)$ \\
\hline Median age (years) & 53 (range 30-70) \\
Gender & \\
Male & $48(84.2)$ \\
Female & $9(15.8)$ \\
ECOG performance & \\
$0-1$ & $47(82.5)$ \\
2 & $9(15.8)$ \\
3 & $1(1.8)$ \\
Etiology & \\
HBV & $45(78.9)$ \\
HCV & $4(7.0)$ \\
Others & $9(15.8)$
\end{tabular}

Previous treatment

Transarterial chemoembolization $\quad 43(75.4)$

Hepatic resection $15(26.3)$

Liver transplantation $\quad 8(14.0)$

Metastatectomy $6(10.5)$

Radiation therapy 6 (10.5)

Percutaneous ethanol injection 7 (12.3)

None

Median no. of TACE

3 (range 1-13)

Child-Pugh class

A

$53(93.0)$

B

$4 \quad(7.0)$

Portal vein thrombosis

Yes

$11(19.3)$

No

$46(80.7)$

$\alpha$ fetoprotein $(\mathrm{ng} / \mathrm{ml})$

Median 1,480

$<400$ (range 0-3,040,000)

$22(38.6)$

$400-10,000 \quad 22(38.6)$

$>10,000$

$13(22.8)$

Extrahepatic metastasis site

Lung $\quad 37$ (64.9)

Lymph node $11(19.3)$

Bone $9(15.8)$

Brain 2 (3.5)

Adrenal gland 2 (3.5)

Peritoneum 1 (1.8)

ECOG, Eastern Cooperative Oncology Group; HBV, hepatitis B virus; $\mathrm{HCV}$, hepatitis $\mathrm{C}$ virus; TACE, transarterial chemoembolization. ${ }^{\mathrm{a} O n e}$ patient had both HBV and HCV.

Statistical analysis. This trial was designed to test the null hypothesis that the response rate was at most $10 \%$ against the alternative hypothesis that it was at least $20 \%$. A sample size of 57 patients provided $80 \%$ power to test this hypothesis, with a one-sided $\alpha-0.10$. 
Table II. Treatment-related toxicity (per patient).

\begin{tabular}{|c|c|c|}
\hline \multirow{2}{*}{$\begin{array}{l}\text { Toxicity } \\
\text { (NCI-CTC) }\end{array}$} & \multicolumn{2}{|c|}{ No. of patients (\%) } \\
\hline & Grade 1-2 & Grade 3-4 \\
\hline Leucopenia & $17(29.8)$ & $6(10.5)$ \\
\hline Neutropenia & $14(24.6)$ & $12(21.1)$ \\
\hline Anemia & $3 \quad(5.3)$ & $0 \quad(0.0)$ \\
\hline Thrombocytopenia & $9(15.8)$ & $5 \quad(8.8)$ \\
\hline Nausea & $15(26.3)$ & $3(5.3)$ \\
\hline Vomiting & $9(15.8)$ & $\begin{array}{ll}0 & (0.0)\end{array}$ \\
\hline Mucositis & $4 \quad(7.0)$ & 1 (1.8) \\
\hline Hepatotoxicity & $6(10.5)$ & $3(5.3)$ \\
\hline Diarrhea & $2(3.5)$ & $\begin{array}{ll}0 & (0.0)\end{array}$ \\
\hline Neuropathy & $2(3.5)$ & $0 \quad(0.0)$ \\
\hline
\end{tabular}

Two patients developed febrile neutropenia and one died. NCI-CTC, National Cancer Institute Common Toxicity Criteria.

The statistical analyses of $2 \times 2$ contingency tables of categorical variables were performed using the Pearson's $\chi^{2}$ or the Fisher's exact test where appropriate. Time to progression (TTP) was determined as the interval between the initiation of chemotherapy and the date when disease progression was first documented. Overall survival (OS) was measured from the date of chemotherapy initiation to the date of death. Median TTP and OS were calculated using the Kaplan-Meier method. The associations of prognostic factors with survival were estimated with Cox's proportional hazard model. Multivariate analyses were carried out using a logistic regression model for response and Cox's proportional hazard models for TTP and OS. The potential prognostic factors (18) included for multivariate analyses were as follows: sex, age ( $<55$ vs. $\geq 55$ years $)$, Child-Pugh class (A vs. B), performance (ECOG 0-1 vs. 2-3), portal vein thrombosis and AFP response. All values were two-sided, and statistical significance was defined as $\mathrm{p}<0.05$. SPSS version 12.0 (SPSS Inc., Chicago, IL, USA) was used for all statistical analyses.

\section{Results}

Tumor response and survival. From March 2003 to February 2006, a total of 57 patients ( 48 men and 9 women, median age 53 years, range $30-70$ ) were enrolled in this study. The clinical characteristics of the patients are summarized in Table I. A total of 190 courses of 5-FU/cisplatin were delivered with a median number of 3 cycles per patient (range 1-8). Mean relative dose intensity was $75.2 \%$. Twenty-five patients had pathologically-confirmed $\mathrm{HCC}$, and the others were clinically diagnosed as described previously.

One patient achieved a complete response (1.8\%) and 7 achieved partial responses $(12.3 \%)$, an overall response rate of $14.1 \%$. Seventeen patients reached stable disease $(29.8 \%)$, and 32 experienced disease progression $(56.1 \%)$, a disease control rate $(\mathrm{CR}+\mathrm{PR}+\mathrm{SD})$ of $43.9 \%$. The median duration of TTP was
Table III. Correlation between clinical variables and radiologic response rates.

\begin{tabular}{lccc}
\hline Variables & $\begin{array}{c}\text { No. of } \\
\text { patients }\end{array}$ & $\begin{array}{c}\text { Responders } \\
(\text { RR \% })\end{array}$ & p-value \\
\hline $\begin{array}{l}\text { Gender } \\
\text { Male }\end{array}$ & 48 & $8(16.7)$ & 0.332 \\
Female & 9 & $0 \quad(0.0)$ & \\
Age & & & \\
$\quad<55$ & 32 & $3 \quad(9.4)$ & 0.280 \\
$\geq 55$ & 25 & $5(20.0)$ & \\
ECOG performance & & & \\
$0-1$ & 47 & $8(17.0)$ & 0.327 \\
$2-3$ & 10 & $0(0.0)$ & \\
Child-Pugh class & & & \\
A & 53 & $7(13.2)$ & 0.464 \\
B & 4 & $1(25.0)$ & \\
Portal vein thrombosis & & & \\
Yes & 11 & $1(9.1)$ & 0.559 \\
No & 46 & $7(15.2)$ & \\
$\alpha$ fetoprotein response & & & \\
Yes & 15 & $5(33.5)$ & 0.012 \\
No & 30 & $1(3.3)$ & \\
\hline
\end{tabular}

RR, response rate; ECOG, Eastern Cooperative Oncology Group.

2.4 months [95\% confidence interval (CI), 1.6-3.3 months] and the median OS was 9.8 months (95\% CI, 2.6-17.0 months). Fig. 1 shows the survival curves for TTP and OS.

Toxicity. The main grade 3 and 4 toxicities (per patient) were leucopenia $(10.5 \%)$, neutropenia $(21.0 \%)$, thrombocytopenia $(8.8 \%)$ and transaminase elevation $(5.3 \%)$ (Table II). Nonhematologic toxicities were mild and manageable. Two patients developed febrile neutropenia and one died. Spontaneous bacterial peritonitis occurred in one patient, but immediately improved after prompt antibiotic therapy. Toxicities were generally reversible and manageable.

Correlation between clinical variables and outcome. We conducted further analysis to ascertain predictive or prognostic factors and to identify the role of the AFP response in systemic chemotherapy. Correlations between clinical variables and radiologic response are documented in Table III. Only the AFP response was found to be significantly associated with radiologic response by univariate $(\mathrm{p}=0.012)$ and multivariate analysis ( $\mathrm{p}=0.021$; odds ratio $=28.702 ; 95 \% \mathrm{CI}, 1.676-491.538)$. The AFP response was the only independent predictive factor of response among the variables listed in Table III.

In terms of survival, radiologic response and AFP response were found to be significantly associated with TTP (hazard ratio $=2.342 ; \mathrm{p}=0.023$ and hazard ratio $=2.351 ; \mathrm{p}=0.013$, 

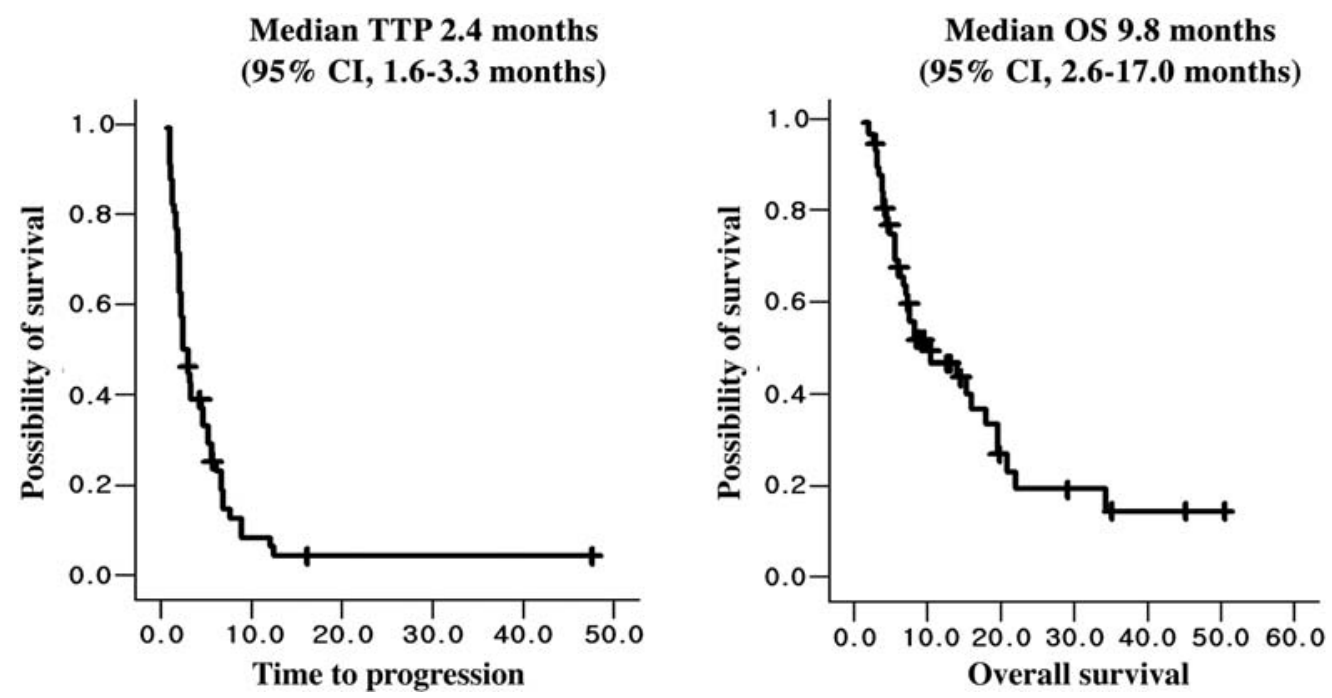

Figure 1. Kaplan-Meier analysis of time to progression (TTP) and overall survival (OS) in hepatocellular carcinoma.

Table IV. Correlation between clinical variables and time to progression.

\begin{tabular}{|c|c|c|c|c|c|c|}
\hline & \multirow[b]{2}{*}{$\begin{array}{l}\text { No. of } \\
\text { patients }\end{array}$} & \multirow[b]{2}{*}{$\begin{array}{l}\text { Median TTP } \\
(95 \% \mathrm{CI})^{\mathrm{a}}\end{array}$} & \multicolumn{2}{|c|}{ Univariate analysis } & \multicolumn{2}{|c|}{ Multivariate analysis } \\
\hline & & & $\begin{array}{l}\text { Hazard ratio } \\
(95 \% \mathrm{CI})^{\mathrm{b}}\end{array}$ & $\mathrm{p}$-value ${ }^{\mathrm{b}}$ & $\begin{array}{c}\text { Hazard ratio } \\
(95 \% \mathrm{CI})^{\mathrm{b}}\end{array}$ & p-value ${ }^{b}$ \\
\hline \multicolumn{7}{|l|}{ Gender } \\
\hline Male & 48 & $2.4(1.3-3.5)$ & $0.763(0.370-1.576)$ & 0.465 & $0.564 \quad(0.217-1.465)$ & 0.240 \\
\hline Female & 9 & $2.8(1.7-3.9)$ & & & & \\
\hline \multicolumn{7}{|l|}{ Age } \\
\hline$<55$ & 32 & $2.4(1.5-3.3)$ & $0.841(0.471-1.502)$ & 0.559 & $0.827 \quad(0.387-1.766)$ & 0.624 \\
\hline$\geq 55$ & 25 & $3.1(0.0-6.3)$ & & & & \\
\hline \multicolumn{7}{|c|}{ ECOG performance } \\
\hline $0-1$ & 47 & $2.8(2.0-3.7)$ & $1.675(0.801-3.497)$ & 0.597 & $1.009 \quad(0.378-2.695)$ & 0.985 \\
\hline $2-3$ & 10 & $2.0(1.1-2.9)$ & & & & \\
\hline \multicolumn{7}{|c|}{ Child-Pugh class } \\
\hline A & 53 & $2.4(1.6-3.3)$ & $1.445(0.516-4.049)$ & 0.483 & $2.623(0.567-12.132)$ & 0.217 \\
\hline $\mathrm{B}$ & 4 & $1.6(0.0-5.5)$ & & & & \\
\hline \multicolumn{7}{|c|}{ Portal vein thrombosis } \\
\hline Yes & 11 & $1.9(1.0-2.8)$ & $0.735(0.366-1.475)$ & 0.386 & $0.764 \quad(0.325-1.794)$ & 0.536 \\
\hline No & 46 & $2.8(1.9-3.7)$ & & & & \\
\hline \multicolumn{7}{|c|}{$\alpha$ fetoprotein response } \\
\hline Yes & 15 & $5.4(3.0-7.9)$ & $2.351(1.194-4.631)$ & 0.013 & $2.569 \quad(1.230-5.365)$ & 0.012 \\
\hline No & 30 & $2.0(1.6-2.4)$ & & & & \\
\hline \multicolumn{7}{|c|}{ Radiologic response } \\
\hline Yes & 8 & $6.7(3.6-9.7)$ & $2.342(0.135-0.865)$ & 0.023 & & \\
\hline No & 49 & $2.2(3.6-9.7)$ & & & & \\
\hline
\end{tabular}

In multivariate analysis, the radiologic response was excluded due to its positive correlation with AFP response. A hazard ratio $>1$ can be thought of as the average increased risk of progression or dying at any point in time compared with the control group (described as above baseline). ${ }^{a}$ Kaplan-Meier analysis; ' ${ }^{\mathrm{C} C o x}$ 's proportional hazard model; TTP, time to progression measured in months; ECOG, Eastern Cooperative Oncology Group.

respectively) (Table IV). However, multivariate analysis indicated that only the AFP response was independently associated with a prolonged TTP (hazard ratio $=2.569 ; 95 \%$
CI, 1.230-5.365; $\mathrm{p}=0.012$ ). In OS, univariate analysis showed that portal vein thrombosis and performance were significantly associated with OS (hazard ratio $=0.429 ; \mathrm{p}=0.045$ and hazard 
Table V. Correlation between clinical variables and overall survival.

\begin{tabular}{|c|c|c|c|c|c|c|}
\hline & \multirow[b]{2}{*}{$\begin{array}{c}\text { No. of } \\
\text { patients }\end{array}$} & \multirow[b]{2}{*}{$\begin{array}{c}\text { Median OS } \\
(95 \% \mathrm{CI})^{\mathrm{a}}\end{array}$} & \multicolumn{2}{|c|}{ Univariate analysis } & \multicolumn{2}{|c|}{ Multivariate analysis } \\
\hline & & & $\begin{array}{l}\text { Hazard ratio } \\
(95 \% \mathrm{CI})^{\mathrm{b}}\end{array}$ & p-value ${ }^{b}$ & $\begin{array}{l}\text { Hazard ratio } \\
(95 \% \mathrm{CI})^{\mathrm{b}}\end{array}$ & p-value ${ }^{b}$ \\
\hline \multicolumn{7}{|l|}{ Gender } \\
\hline Male & 48 & $8.1(5.0-11.2)$ & $0.840 \quad(0.348-2.024)$ & 0.697 & $0.434 \quad(0.133-1.422)$ & 0.168 \\
\hline Female & 9 & $15.2(1.7-28.7)$ & & & & \\
\hline \multicolumn{7}{|l|}{ Age } \\
\hline$<55$ & 32 & $10.3(0.3-20.3)$ & $1.302(0.680-2.494)$ & 0.426 & $1.664 \quad(0.746-3.712)$ & 0.214 \\
\hline$\geq 55$ & 25 & $8.1(0.0-16.3)$ & & & & \\
\hline \multicolumn{7}{|c|}{ ECOG performance } \\
\hline $0-1$ & 47 & $13.9(4.3-23.5)$ & $2.336(1.120-4.878)$ & 0.024 & $2.182(0.865-5.506)$ & 0.098 \\
\hline $2-3$ & 10 & $6.0 \quad(2.7-9.3)$ & & & & \\
\hline \multicolumn{7}{|c|}{ Child-Pugh class } \\
\hline A & 53 & $10.3(3.1-17.6)$ & $1.420 \quad(0.335-6.024)$ & 0.634 & $2.007(0.347-11.610)$ & 0.436 \\
\hline $\mathrm{B}$ & 4 & $7.5(0.0-15.8)$ & & & & \\
\hline \multicolumn{7}{|c|}{ Portal vein thrombosis } \\
\hline Yes & 11 & $4.4 \quad(0.6-8.2)$ & $0.429 \quad(0.188-0.982)$ & 0.045 & $0.729 \quad(0.268-1.983)$ & 0.536 \\
\hline No & 46 & $13.9(5.6-22.2)$ & & & & \\
\hline \multicolumn{7}{|c|}{$\alpha$ fetoprotein response } \\
\hline Yes & 15 & $13.9(2.5-25.3)$ & $1.464 \quad(0.668-3.118)$ & 0.323 & $1.463(0.650-3.291)$ & 0.358 \\
\hline No & 30 & $7.6(0.7-14.5)$ & & & & \\
\hline \multicolumn{7}{|c|}{ Radiologic response } \\
\hline Yes & 8 & Not reached & $3.088(0.740-12.866)$ & 0.122 & & \\
\hline No & 49 & $8.1(4.4-11.7)$ & & & & \\
\hline
\end{tabular}

${ }^{\mathrm{a} K a p l a n-M e i e r}$ analysis; ${ }^{\mathrm{b} C o x}$ 's proportional hazard model. OS, overall survival in months; ECOG, Eastern Cooperative Oncology Group.

ratio=2.336; $\mathrm{p}=0.024$, respectively) (Table V), but multivariate analysis showed no statistical correlation between OS and potential prognostic variables.

AFP response and clinical outcomes. Of the 45 patients who initially had an elevated AFP level (>5 ng/ml), 15 (33.3\%) showed an AFP reduction of $>50 \%$ (mean reduction $76.4 \%$ ), and $53.3 \%$ of these 15 responders showed this AFP reduction after the first cycle of chemotherapy.

The radiologic tumor response rates in AFP responders and non-responders were 33.3 and $3.3 \%$, respectively $(\mathrm{p}=0.012)$ (Table VI). The sensitivity of the AFP response was $83.3 \%$ (5 of 6) and its specificity was $74.4 \%$ (29 of 39). The disease control rate was significantly higher in AFP responders (80.0\% in AFP responders vs. 23.3\% in AFP non-responders, $\mathrm{p}<0.001)$. TTP differed significantly for AFP responders and non-responders; median TTP was 5.4 months (95\% CI, 3.0-7.9 months) in AFP responders and 2.0 months (95\% CI, 1.6-2.4 months) in AFP non-responders $(\mathrm{p}=0.010)$. The median OS of AFP responders and non-responders was 13.9 months (95\% CI, 2.5-25.3 months) and 7.6 months (95\% CI, 0.7-14.5 months) $(\mathrm{p}=0.317)$. TTP and OS survival curves for AFP responders and non-responders are shown in Fig. 2.

\section{Discussion}

The antitumor activities of a number of chemotherapeutic agents against $\mathrm{HCC}$ remain poor; low response rates are often not reproducible, and consequently systemic chemotherapy has been shown to have a negligible effect on survival. However, some studies have indicated that aggressive chemotherapy may result in complete pathologic remission (9). Therefore, it is important that we continue to search for and develop more effective systemic chemotherapies, including novel agents.

In this study, we investigated the antitumor effect and toxicity of 5-FU/cisplatin combination chemotherapy. With an overall response rate of $14.1 \%$, a disease control rate of $43.9 \%$ and a median OS of 9.8 months (95\% CI, 2.6-17.0 months), our results compare favorably with those of chemotherapeutic regimens previously used in HCC. The mean relative dose intensity level was $75.2 \%$, which was not higher than other chemotherapies in gastrointestinal cancer. This may have been caused by thrombocytopenia and leucopenia, which arose from underlying liver cirrhosis and sequestration at the spleen.

The response rate of this regimen was comparable to those of other Phase II studies of 5-FU-based combination chemotherapy, which ranged from 14.3 to $27.0 \%(7,9,19,20)$. 
Table VI. Characteristics and clinical outcomes of $\alpha$ fetoprotein responders and non-responders.

\begin{tabular}{|c|c|c|c|}
\hline \multirow[b]{2}{*}{ Characteristics $(n=45)$} & \multicolumn{3}{|c|}{ No. of patients (\%) } \\
\hline & AFP responders & AFP non-responders & p-value \\
\hline Median age (range) & $51(30-68)$ & $55(36-70)$ & $0.769^{c}$ \\
\hline \multicolumn{4}{|l|}{ Gender } \\
\hline Male & $13(86.7)$ & $25(73.3)$ & 0.771 \\
\hline Female & $2(13.3)$ & $5(16.7)$ & \\
\hline \multicolumn{4}{|l|}{ ECOG performance } \\
\hline $0-1$ & $12(80.0)$ & $24(80.0)$ & 0.755 \\
\hline 2 & $3(20.0)$ & $5(16.7)$ & \\
\hline 3 & $0 \quad(0.0)$ & $1 \quad(3.3)$ & \\
\hline \multicolumn{4}{|l|}{ Etiology } \\
\hline $\mathrm{HBV}$ & $11(73.3)$ & $26(89.7)$ & 0.160 \\
\hline $\mathrm{HCV}$ & $0 \quad(0.0)$ & 1 (3.4) & \\
\hline Others & $4(26.7)$ & $2(6.9)$ & \\
\hline Median no. of TACE & 2 (range $1-10$ ) & 3 (range 1-13) & $0.738^{\mathrm{c}}$ \\
\hline \multicolumn{4}{|l|}{ Child-Pugh class } \\
\hline A & $14(93.3)$ & $28(93.3)$ & 1.000 \\
\hline $\mathrm{B}$ & $1 \quad(6.7)$ & $2(6.7)$ & \\
\hline \multicolumn{4}{|l|}{ Portal vein thrombosis } \\
\hline Yes & $13(86.7)$ & $8(26.7)$ & 0.310 \\
\hline No & $2(13.3)$ & $22(73.3)$ & \\
\hline \multicolumn{4}{|l|}{$\alpha$ fetoprotein $(\mathrm{ng} / \mathrm{ml})$} \\
\hline$<400$ & $5(33.3)$ & $5(16.7)$ & 0.106 \\
\hline $400-10,000$ & $4(26.7)$ & $18(60.0)$ & \\
\hline$>10,000$ & $6(40.0)$ & $7(23.3)$ & \\
\hline Radiologic responder ${ }^{\mathrm{a}}$ & $5(33.3)$ & $1 \quad(3.3)$ & 0.012 \\
\hline Non-responder & $10(66.7)$ & $29(96.7)$ & \\
\hline Disease control $^{\mathrm{b}}$ & $12(80.0)$ & $7(23.3)$ & $<0.001$ \\
\hline Progressive disease & $3(20.0)$ & $23(76.7)$ & \\
\hline Median TTP (months) $(95 \% \mathrm{CI})$ & $5.4 \quad(3.0-7.9)$ & $2.0 \quad(1.6-2.4)$ & $0.010^{\mathrm{d}}$ \\
\hline Median OS (months) $(95 \% \mathrm{CI})$ & $13.9(2.5-25.3)$ & $7.6(0.7-14.5)$ & $0.317^{\mathrm{d}}$ \\
\hline
\end{tabular}

${ }^{a}$ Radiologic responder, complete response + partial response. ${ }^{b}$ Disease control, complete response + partial response + stable disease. p-values were based on the ${ }^{\mathrm{c} S}$ Student $\mathrm{t}$-test or ${ }^{\mathrm{d}} \log$ rank test. Otherwise, $\mathrm{p}$-values were based on the $\chi^{2}$ test. AFP, $\alpha$ fetoprotein; ECOG, Eastern Cooperative Oncology Group; TACE, transarterial chemoembolization; TTP, time to progression; OS, overall survival.

However, because of the marginal antitumor activity of systemic chemotherapy, it is necessary to select patients who are likely to benefit from chemotherapy by identifying parameters that reflect response and prognosis. Serum AFP is one such promising surrogate marker, which is currently used to screen for early and operable stage HCC.

In the present study, the AFP response rate was $33.3 \%$, which was identical to the previously-reported $32.4 \%$ (21), and AFP response was found to be significantly correlated with radiologic response. Multivariate analysis showed it to be an independent predictive marker of radiologic response (odds ratio, 28.702; $\mathrm{p}=0.021$ ). AFP response was also associated with prolonged TTP by multivariate analysis (hazard ratio, 2.509; $\mathrm{p}=0.015$ ), but not with OS. Moreover, AFP response was statistically more strongly associated with prolonged TTP than radiologic response. These findings suggest that even HCC patients who do not meet the criteria for radiographic tumor response may benefit from 5-FU/cisplatin chemotherapy in terms of TTP, if not OS. After disease progression, an abrupt rise in AFP was observed in the AFP responder group. This phenomenon suggests that, after the cessation of chemotherapy, the AFP responder group may have exhibited more aggressive biologic behavior than the AFP non-responder indolent group. In the present study, it appears that the small number of patients involved impeded clarification of the relation between AFP response and OS. In advanced HCC patients treated with thalidomide, a similar finding was observed; AFP response served as a prognostic marker of survival (22). 

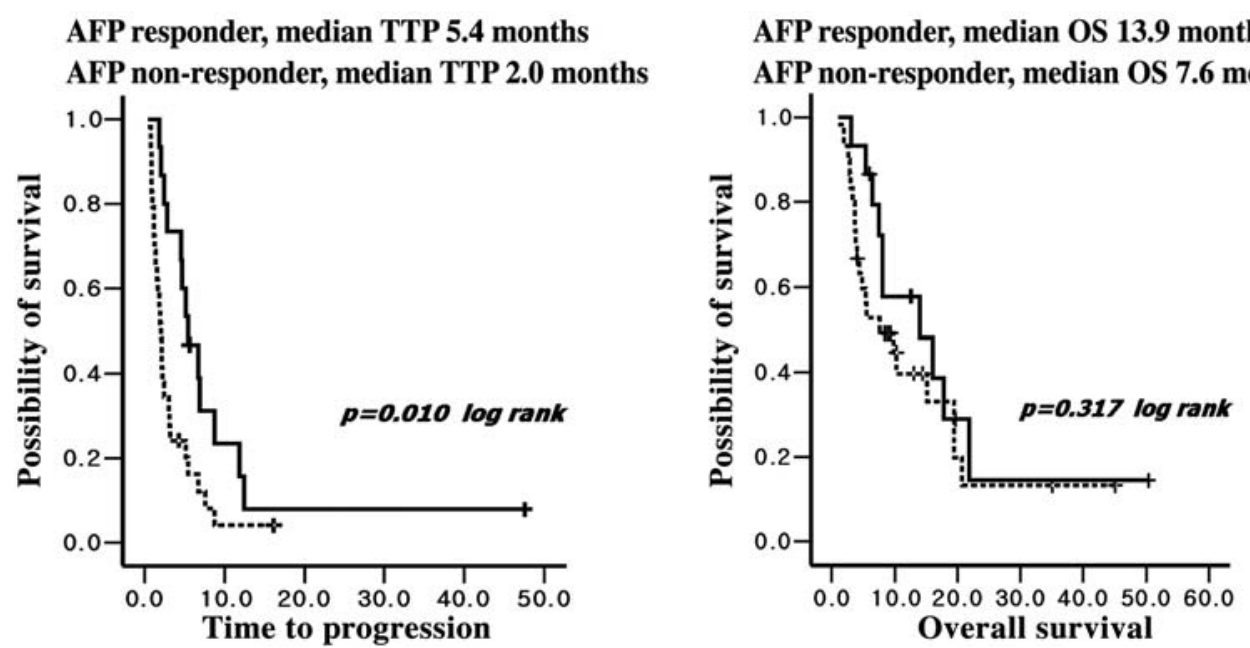

Figure 2. Kaplan-Meier analysis of time to progression (TTP) and overall survival (OS) in hepatocellular carcinoma patients with an elevated baseline $\alpha$ fetoprotein (AFP) response level. AFP responders, solid line; AFP non-responders, dotted line.

Moreover, in the present study, the majority of AFP responders (53.3\%) showed a reduction in AFP after the first cycle of chemotherapy. This rapid decline implies that AFP has a possible role to play as an early response marker prior to follow-up computed tomography, and also suggests that AFP non-responders may not benefit from 5-FU/cisplatin chemotherapy. Consequently, it would be possible to avoid toxicity without clinical benefit.

It remains to be proved whether an AFP decline reflects the cell death of AFP-producing tumor cells, or whether it reflects the modulation of AFP production from tumor cells. However, there is a discrepancy between the radiologic and biologic responses in $\mathrm{HCC}$ (9), and an additional marker that could reflect biologic response would aid in the identification of those patients likely to benefit from chemotherapy. Further identification of the molecular, genetic and biological factors associated with AFP response is mandatory.

In terms of toxicity, the study regimen was tolerated. The spectrum of both hematologic and non-hematologic toxicity was reversible and manageable.

The present study was not without limitations. We did not measure another complementary tumor marker, such as protein induced by vitamin K absence or antagonist II (PIVKA-II). Our study population was relatively heterogeneous in terms of their previous treatments. Furthermore, a significant portion of the patients had already been heavily treated by locoregional treatments such as TACE (median no., 3). However, treatment with 5-FU/cisplatin showed a modest antitumor effect even in these heavily treated patients.

In conclusion, given a disease control rate of $43.9 \%, 5-\mathrm{FU} /$ cisplatin chemotherapy appears to have modest disease control activity and acceptable toxicity in patients with inoperable HCC. The AFP response was found to be a useful predictive marker of response in HCC patients administered 5-FU/ cisplatin, and was found to be an independent indicator of prolonged TTP. Thus, AFP response may reflect the biologic response more than the radiologic one. However, the observed limited prognostic reliability of AFP response for OS requires further investigation.

\section{Acknowledgements}

This study was supported in part by a grant from the National R\&D Program for Cancer Control, Ministry of Health and Welfare, Korea (06203000-1).

\section{References}

1. Ng IO, Liu CL, Fan ST and Ng M: Expression of P-glycoprotein in hepatocellular carcinoma. A determinant of chemotherapy response. Am J Clin Pathol 113: 355-363, 2000.

2. Chou YY, Cheng AL and Hsu HC: Expression of P-glycoprotein and p53 in advanced hepatocellular carcinoma treated by single agent chemotherapy: clinical correlation. J Gastroenterol Hepatol 12: $569-575,1997$.

3. Okada S: Chemotherapy in hepatocellular carcinoma. Hepatogastroenterology 45: 1259-1263, 1998.

4. Di Maio M, De Maio E, Perrone F, Pignata S and Daniele B: Hepatocellular carcinoma: systemic treatments. J Clin Gastroenterol 35: S109-S114, 2002.

5. Yodono H, Sasaki T, Tarusawa K, Midorikawa H, Saito Y and Takekawa SD: Arterial infusion chemotherapy for advanced hepatocellular carcinoma using EPF and EAP therapies. Cancer Chemother Pharmacol 31: S89-S92, 1992.

6. Toyoda H, Nakano S, Takeda I, Kumada T, Sugiyama K and Osada T: The study of continuous local arterial-infusion chemotherapy with 5-FU + CDDP for patients with severely advanced $\mathrm{HCC}$ - for the elongation of the life-span and the improvement of QOL. Gan To Kagaku Ryoho 20: 1495-1498, 1993.

7. Patt YZ, Hassan MM, Lozano RD, Brown TD, Vauthey JN, Curley SA and Ellis LM: Phase II trial of systemic continuous fluorouracil and subcutaneous recombinant interferon alpha- $2 b$ for treatment of hepatocellular carcinoma. J Clin Oncol 21: 421-427, 2003.

8. Leung TW, Tang AM, Zee B, Yu SC, Lai PB, Lau WY and Johnson PJ: Factors predicting response and survival in 149 patients with unresectable hepatocellular carcinoma treated by combination cisplatin, interferon-alpha, doxorubicin and 5-fluorouracil chemotherapy. Cancer 94: 421-427, 2002.

9. Leung TW, Patt YZ, Lau WY, Ho SK, Yu SC, Chan AT, Mok TS, Yeo W, Liew CT, Leung NW, Tang AM and Johnson PJ: Complete pathological remission is possible with systemic combination chemotherapy for inoperable hepatocellular carcinoma. Clin Cancer Res 5: 1676-1681, 1999.

10. Farinati F, Marino D, De Giorgio M, Baldan A, Cantarini M, Cursaro C, Rapaccini G, Del Poggio P, Di Nolfo MA, Benvegnu L, Zoli M, Borzio F, Bernardi M and Trevisani F: Diagnostic and prognostic role of alpha-fetoprotein in hepatocellular carcinoma: both or neither? Am J Gastroenterol 101: 524-532, 2006. 
11. Gorog D, Regoly-Merei J, Paku S, Kopper L and Nagy P: Alphafetoprotein expression is a potential prognostic marker in hepatocellular carcinoma. World J Gastroenterol 11: 5015-5018, 2005.

12. Tangkijvanich P, Anukulkarnkusol N, Suwangool P, Lertmaharit S, Hanvivatvong O, Kullavanijaya P and Poovorawan Y: Clinical characteristics and prognosis of hepatocellular carcinoma: analysis based on alpha-fetoprotein levels. J Clin Gastroenterol 31: 301-308, 2000.

13. Bruix J, Sherman M, Llovet JM, Beaugrand M, Lencioni R, Burroughs AK, Christensen E, Pagliaro L, Colombo M, Rodes J and the EASL Panel of Experts on HCC: Clinical management of hepatocellular carcinoma. Conclusions of the Barcelona-2000 EASL conference. European Association for the Study of the Liver. EASL Panel of Experts on HCC. J Hepatol 35: 421-430, 2001.

14. Miller AB, Hoogstraten B, Staquet M and Winkler A: Reporting results of cancer treatment. Cancer 47: 207-214, 1981

15. Lee HS, Kim KM, Yoon JH, Lee TR, Suh KS, Lee KU, Chung JW, Park JH and Kim CY: Therapeutic efficacy of transcatheter arterial chemoembolization as compared with hepatic resection in hepatocellular carcinoma patients with compensated liver function in a hepatitis $\mathrm{B}$ virus-endemic area: a prospective cohort study. J Clin Oncol 20: 4459-4465, 2002.

16. Rustin GL: Use of CA-125 to assess response to new agents in ovarian cancer trials. J Clin Oncol 21: S187-S193, 2003.

17. Bubley GJ, Carducci M, Dahut W, Dawson N, Daliani D, Eisenberger M, Figg WD, Freidlin B, Halabi S, Hudes G, Hussain M, Kaplan R, Myers C, Oh W, Petrylak DP, Reed E, Roth B, Sartor O, Scher H, Simons J, Sinibaldi V, Small EJ, Smith MR, Trump DL and Wilding G: Eligibility and response guidelines for phase II clinical trials in androgen-independent prostate cancer: recommendations from the Prostate-specific Antigen Working Group. J Clin Oncol 17: 3461-3467, 1999.
18. Chevret S, Trinchet JC, Mathieu D, Rached AA, Beaugrand M and Chastang C: A new prognostic classification for predicting survival in patients with hepatocellular carcinoma. Groupe d'Etude et de Traitement du Carcinome Hepatocellulaire. J Hepatol 31: 133-141, 1999.

19. Ikeda M, Okusaka T, Ueno H, Takezako Y and Morizane C: A phase II trial of continuous infusion of 5-fluorouracil, mitoxantrone, and cisplatin for metastatic hepatocellular carcinoma. Cancer 103: 756-762, 2005.

20. Boucher E, Corbinais S, Brissot P, Boudjema K and Raoul JL: Treatment of hepatocellular carcinoma (HCC) with systemic chemotherapy combining epirubicin, cisplatinum and infusional 5-fluorouracil (ECF regimen). Cancer Chemother Pharmacol 50: 305-308, 2002.

21. Lee J, Park JO, Kim WS, Park SH, Park KW, Choi MS, Lee JH, Koh KC, Paik SW, Yoo BC, Joh J, Kim K, Jung CW, Park YS, Im YH, Kang WK, Lee MH and Park K: Phase II study of doxorubicin and cisplatin in patients with metastatic hepatocellular carcinoma. Cancer Chemother Pharmacol 54: 385-390, 2004.

22. Chen LT, Liu TW, Chao Y, Shiah HS, Chang JY, Juang SH, Chen SC, Chuang TR, Chin YH and Whang-Peng J: Alphafetoprotein response predicts survival benefits of thalidomide in advanced hepatocellular carcinoma. Aliment Pharmacol Ther 22: 217-226, 2005. 